\title{
Spatial and Temporal Dynamics of a Fungal Pathogen Promote Pattern Formation in a Tropical Agroecosystem
}

\author{
Doug Jackson ${ }^{*}, 1$, John Vandermeer ${ }^{1,2}$ and Ivette Perfecto ${ }^{2}$ \\ ${ }^{I}$ Department of Ecology and Evolutionary Biology, ${ }^{2}$ School of Natural Resources and Environment, University of \\ Michigan, Ann Arbor, MI 48109, USA
}

\begin{abstract}
Recent studies have shown that the spatial pattern of nests of an arboreal ant, Azteca instabilis (Hymenoptera: Formicidae), in a tropical coffee agroecosystem may emerge through self-organization. The proposed self-organization process involves both local expansion and density-dependent mortality of the ant colonies. We explored a possible mechanism for the density-dependent mortality involving the entomopathogenic fungus Lecanicillium lecanii. L. lecanii attacks a scale insect, Coccus viridis (Coccidae, Hemiptera), which is tended by A. instabilis in a mutualistic association. By attacking $C$. viridis, L. lecanii may have an indirect, negative effect on ant colony survival. To explore this hypothesis, we conducted investigations into the spatial and temporal distributions of $L$. lecanii. We measured incidence and severity at 4 spatial scales: (1) throughout a 45 hectare study plot; (2) in two 40 X 50 meter plots; (3) on coffee bushes within 4 m of two ant nests; and (3) on individual branches in a single coffee bush. The plot-level censuses did not reveal a clear spatial pattern, but the finer scale surveys show distinct patterns in the spread of infection over time. We also developed a simple cellular automata model of the coupled ant nest- $L$. lecanii system which is able to produce spatial patterns qualitatively and quantitatively similar to that found in the field. The accumulated evidence suggests that $L$. lecanii may very well be responsible for the density-dependent control thought necessary for spatial pattern formation of ant nests in this system.
\end{abstract}

Keywords: Azteca instabilis, Coccus viridis, Lecanicillium lecanii, coffee agroecosystem, self-organization, spatial pattern, cellular automata, entomopathogen.

\section{INTRODUCTION}

It is familiar knowledge in ecology first, that patterns in space are both striking and important and second, that complex interacting networks surround every population of every organism. It is only recently that these two issues have come together in a mutually reflective way, leading to a fundamental question of causality - does the spatial pattern determine the details of the interacting network or does the spatial pattern result from that network? While the existence of spatial patterns in extended landscapes has long been appreciated, it has frequently been assumed that they emerge from underlying habitat variables, which implicitly takes the pattern as an independent variable which determines the nature of population interactions of the species living in the landscape. It is only recently that a great deal of theoretical work has been devoted to demonstrating the possibility of the opposite causality, that the pattern itself is caused by the population interactions (Rohani et al. 1997, Bascompte \& Solé 1998, Pascual et al. 2002, Rietkerk et al. 2002, Scanlon et al. 2007). Here we contribute to this debate with the suggestion that a fungal disease attacking the food of an ant ultimately causes the distributional patterns of the ant nests.

Recent studies have shown that the spatial distribution of the nests of an arboreal ant Azteca instabilis (Formica,

*Address correspondence to this author at the Department of Ecology and Evolutionary Biology, University of Michigan, Ann Arbor, MI 48109, USA; Tel: 734-764-1446; Fax: 734-763-0544; E-mail: dougjack@umich.edu Handling Editor: Philip H. Crowley
Hymenoptera) in a coffee agroecosystem may emerge through self-organization (Vandermeer et al. 2008, Perfecto \& Vandermeer 2008). The ant A. instabilis builds nests in shade trees within the system and tends a species of scale insect (Coccus viridis, Coccidae, Hemiptera), which resides in the coffee bushes, in a classic ant/Hemipteran mutualistic association. The proposed self-organization process has been studied with the aid of a cellular automata model which involves local effects for both expansion and densitydependent mortality of the ant colonies (Vandermeer et al. 2008; Vandermeer and Jackson, under revision). The local expansion process is obvious from casual field observations, arising when ant colonies establish satellite colonies in neighboring trees. However, the cause of the densitydependent mortality is less evident. It has been attributed to the attack of a dipteran parasitoid (Pseudacteon sp., Phoridae), although evidence for this mechanism is only correlative (Vandermeer et al. 2008). Indeed there are a variety of other processes that could be responsible for the proposed density-dependent mortality. The most evident alternatives include a beetle (Azya orbigera, Coccinellidae, Coleoptera) that is a primary predator of $C$. viridis (Liere \& Perfecto 2008), and an entomopathogenic fungus, Lecanicillium lecanii, that infects $C$. viridis. In this report, we discuss our investigation into the possibility that this latter candidate, the white halo fungus Lecanicillium lecanii, could be the source of density-dependent control.

L. lecanii, previously known as Cephalosporium lecanii, is part of what had been identified as the Verticillium lecanii species complex (Kouvelis et al. 1999, Gams \& Zare 2001). 
These entomopathogenic fungi are known to attack a variety of arthropods, many of which are important agricultural pests (Hsiao et al. 1992, Chandler et al. 1993, Helyer 1993, Gindin et al. 1996, Michaud \& Browning 1999, Gindin et al. 2000, Rodríguez Dos Santos \& del Pozo Núñez 2003) including $C$. viridis in coffee (Easwaramoorthy \& Jayaraj 1978, Bhaskara \& Krishnamoorthy Bhat 1989, Uno 2007). It is also marketed as a biocontrol agent (Hall 1981, Khalil et al. 1984/85, Khalil et al. 1985, Ravensberg et al. 1990, Feng et al. 2000). In our study site, L. lecanii often creates a local epizootic, killing nearly all of the $C$. viridis on a single coffee bush or a small group of neighboring bushes (personal observations). The importance of honeydew to Hemipteratending ants (Helms \& Bradleigh Vinson 2008) suggests that such a decimation of a colony's scale populations would substantially decrease colony growth and survival. Therefore, $L$. lecanii may reduce the amount of carbohydrate food available to an ant colony, resulting in an indirect negative effect on colony survival. Analogous increases in ant colony mortality attributable to a natural enemy attacking an ant colony's mutualist partner have been reported for leafcutting ants, whose fungal cultivars are attacked by mycoparasites (Currie et al. 1999, Currie 2001, Reynolds \& Currie 2004).

To better understand the role of L. lecanii in this system, we investigated the distributions of $L$. lecanii at multiple spatial scales and the temporal dynamics of these distributions. Knowledge of the spatial distribution of the fungus, in terms of incidence and severity, is clearly important for assessing the potential for the fungus to influence the selforganization process. How the spatial distribution changes throughout the course of a local infection is a basic component of L. lecanii's natural history and a clear determinant of its impact on the spatial dynamics of the ant mutualist, Azteca instabilis. We also developed a coupled cellular automata model of the ant nests and fungus to demonstrate that it is possible to generate the observed spatial distribution of ant nests using a very simple model that distills the hypothesized pattern formation mechanism into a few simple functions.

\section{METHODS}

The study site is located at Finca Irlanda, a 300 hectare, organic coffee farm in the Soconusco region of Chiapas, Mexico $\left(15^{\circ} 11^{\prime} \mathrm{N}, 92^{\circ} 20^{\prime} \mathrm{W}\right)$. The farm is a commercial polyculture, with coffee bushes growing beneath trees that have been planted in an approximately uniform distribution. The dominant shade trees are Inga spp., Alchornea latifolia, and Trema micrantha (Martinez \& Peters 1996), some of which have extrafloral nectaries. Previous work had been done by Vandermeer et al. (2008) to map the locations of every shade tree in a 45 hectare plot within the farm and to conduct periodic censuses of $A$. instabilis nest locations. The 45 ha plot is a $600 \mathrm{~m} \mathrm{X} 800 \mathrm{~m}$ rectangle with a $100 \mathrm{~m} \mathrm{X} 300$ $\mathrm{m}$ rectangle excluded from one corner of the plot due to the inaccessibility of the terrain. There are $\approx 11,000$ shade trees in the 45 ha plot, of which $\approx 300$ contain ant nests. The spatial distribution of the ant nests is clumped, with a mean/variance ratio significantly different from a random distribution, and a cluster size distribution that is thought to be characteristic of robust criticality (Vandermeer et al. 2008).

To assess the distribution of the fungus at a large scale, the 45 ha plot was divided into $50 \mathrm{~m}$ X $50 \mathrm{~m}$ quadrats. Using the available ant nest census data, the shade tree containing an ant nest that was closest to the center of each quadrat was identified. Since the purpose of the survey was to determine the potential for the fungus to contribute to the mortality of existing ant nests, quadrats without ant nests were excluded from the survey. Quadrats at the edge of the plot were also excluded to avoid including areas that might be influenced by unknown factors existing outside of the censused area. The incidence and severity of the fungus were measured in the coffee bushes neighboring each of 56 shade trees between July 8 and Aug 1, 2006. Due to the time required to locate and travel to each shade tree, the order in which the trees were surveyed was determined by their geographic location; time constraints prevented a random survey sequence.

Neighboring coffee bushes were defined as those directly adjacent to the shade tree or within $2 \mathrm{~m}$, whichever resulted in a larger number of bushes. This was necessary because in some locations the nearest bushes were $>2 \mathrm{~m}$ from the shade tree, while in others it was impractical to survey all of the coffee bushes in an area with a radius larger than $2 \mathrm{~m}$.

Every branch on every neighboring coffee bush was inspected to see if any scales had been infected. As suggested by its name, "white halo fungus," it is obvious when a scale is in the later stages of infection by L. lecanii; the mycelial mat of the fungus forms a distinctive white ring around the infected scale, which is normally a bright green color. If a fungal infection was detected in a location, the severity was ranked as high, low, or medium, as follows: high $=$ one or more neighboring coffee bushes with a scale population with very high levels of mortality due to $L$. lecanii, i.e., having multiple branches with $>50 \%$ scale mortality; low $=$ one or more neighboring coffee bushes with $<10$ scales killed by L. lecanii; and medium = one or more coffee bushes with fungal mortality between the low and high levels.

The large-scale spatial distribution of the fungus was analyzed using Ripley's K, transformed such that the expectation for all sample sizes is zero for a random spatial pattern and greater than zero for clustered patterns (Goreaud \& Pélissier 1999). The survey data were compared by the Monte Carlo method, using 1000 simulated Poisson patterns of fungus presence/absence at the sample locations used in the fungus survey, i.e., accounting for the underlying nonrandom distribution of the sample points.

To study distribution and dynamics at an intermediate scale, we identified two clusters of $A$. instabilis nests. Site A had a cluster of four trees and had been intensively studied four years ago, including detailed surveys of scale insects on coffee bushes at various distances from the central $A$. instabilis nest. Four years ago only one of the four trees was occupied by an ant nest, three years ago two trees were occupied, and beginning in 2007 all four trees were occupied. Site B had no ant nests at all during the original census of 2004 and six trees occupied in the 2007 and 2008 censuses, with the three central nests appearing to be the 
oldest of the six. Thus, by 2008, site A was an "old" site, having been occupied by $A$. instabilis at least since our study began in 2004, while site B was a "new" site, clearly unoccupied in 2004 but having six trees occupied by 2007 . At both sites A and B we examined coffee bushes at various distances from the central nest, establishing spatial coordinates for each of the trees examined. For each bush we chose the largest main stem, or for very small bushes we examined the entire plant, and systematically assessed each branch for scale insects and fungal $(L$. lecanii) attack. For making a rapid assessment, we categorized branches, with regard to scale insects, as 1) very low (between 1 and 5 scales), 2) low (between 5 and 25 scales), 3) medium (between 25 and 75), 4) high (between 75 and 125), and 5) very high (more than 125). These assessments were translated into numbers (very low $=2$, low $=10$, medium $=$ 50 , high $=100$, and very high $=200$ ), and data represented as average number of scales per branch. In site A 149 bushes and in site B 132 bushes were examined. Assessment of $L$. lecanii infection was based on a percentage, regardless of the number of scales involved (if there was only one scale insect on a branch but it was infected with fungus, the branch was categorized as $100 \%$ infected). Intensity of infection was then represented as the number of infected scales per branch.

At the level of individual shade trees, we identified two shade trees with ant nests and high levels of fungal infection, i.e., with large scale populations ( $>>100$ scales) exhibiting a high incidence of fungal mortality. The locations of every coffee bush within $4 \mathrm{~m}$ of the central shade trees were measured. The total number of branches, the number of branches with uninfected scale populations, and the number of branches with infected scale populations were counted on each bush during three censuses. Branches with one or more individual scales infected by $L$. lecanii were categorized as "infected." Shade tree \#1 was censused on July 6, July 19, and August 5, 2006. Shade tree \#2 was censused on July 8, July 25, and August 7, 2006.

To study dynamics at a smaller scale, a single coffee plant with scale populations in the beginning stages of infection was chosen. There were 4 individual shoots on this plant. Each branch was marked with a letter indicating the shoot (A-D) and a number indicating the branch, starting with the lowest branches, e.g., A1. The healthy and infected scales on each branch were counted on July 7 , July 24 , and August 6, 2006; only large ( $>\approx 2 \mathrm{~mm}$ ) scales were counted.

To test the plausibility of the hypothesis that $L$. lecanii acts as the inhibitor in the spatial self-organization process (as elaborated more completely in the discussion), we created a cellular automata model (CA) representing the spatially explicit epizoology of $A$. instabilis and L. lecanii. The model is a version of the ant CA developed by Vandermeer et al. (2008) modified to include the spatial distribution and dynamics of L. lecanii. As in the original ant CA model, the 45 ha study plot is represented by a $90 \times 120$ lattice. Each cell in the lattice can be in one of three states: empty, occupied by an ant nest whose scale insect populations are free of $L$. lecanii, or occupied by an ant nest whose scale insects are infected by L. lecanii. As in the original formulation of the model (Vandermeer et al. 2008), the probability of an empty cell being occupied by a new ant nest via satellite expansion of a neighboring nest is a linear function of the number of occupied nests in the eight-cell Moore neighborhood, $\mathrm{N}\left(\mathrm{p}_{\mathrm{s}}=s_{0}+s_{l} \mathrm{~N}\right.$ for $\mathrm{N}>0 ; \mathrm{p}_{\mathrm{s}}=0$ for $\mathrm{N}$ $=0)$. The satellite expansion parameter values used in Vandermeer et al. (2008), which were based on field census data, are also used in this extended version of the model $\left(s_{0}=\right.$ $0.0035, s_{l}=0.035$ ). Ant nest mortality, which in the original model was a probabilistic function of the number of neighboring ant nests, is now a function $L$. lecanii infection. If infected, the probability of ant nest mortality is equal to the virulence of the fungus, $v$; otherwise, the probability of nest mortality is zero. If a nest at an infected site survives one time step, the site remains infected in subsequent time steps until the nest dies, i.e., there is no recovery. Transmission of the fungus into an uninfected ant nest is analogous to the ant nest satellite expansion function: the probability of transmission is a linear function of the number of infected nests in the Moore neighborhood, $\mathrm{F}\left(\mathrm{p}_{\mathrm{t}}=t_{0}+t_{l} \mathrm{~F}\right.$ for $\mathrm{F}>0$ ). In addition, there is a very small probability, $a$, that an uninfected site with no infected neighbors will become infected; this is necessary to prevent the fungus from becoming extinct, but is also biologically reasonable given that $L$. lecanii has been reported to persist in environmental reservoirs, e.g., in the soil (Eapen et al. 2005, Meyling \& Eilenberg 2006); infection of isolated sites, with $F=0$, represents a low probability transmission from an environmental reservoir.

The purpose of the model was to demonstrate that a simple model incorporating the hypothesized biology of the system ( $L$. lecanii-induced mortality or migration of ant nests) could generate the observed spatial distribution. To explore the parameter space of the model, we employed a genetic algorithm (Goldberg 1989, Whitley 1994) to search for values of $v, t_{l}$ and $a$ that could generate a spatial pattern of ant nests qualitatively and quantitatively similar to the pattern observed in the field. While the initial setup and configuration of a genetic algorithm may be slightly more complicated than some other possible optimization algorithms, e.g., hill climbing, our past experience with other spatially explicit models has shown the potential for results to depend on parameters in complex, non-linear, or counterintuitive ways. Since we had no a priori knowledge of the shape of the fitness landscape, we chose to use a genetic algorithm approach because of its ability to find solutions even when the fitness landscape is discontinuous, noisy, or complex. The quantitative targets were a mean/variance ratio of $\approx 0.42$ (a significantly clumped pattern; Monte-Carlo method using 10,000 simulated Poisson patterns with the same density as the field census data; $\mathrm{P}<0.0001$ ) and a density of $\approx 0.03$ nests/shade tree, which are values obtained from the field census data. To reduce the size of the search space, we fixed $\mathrm{t}_{0}=0$ and $a<0.01$ for all runs. We ran each simulation for 1000 time steps and calculated the average density and mean/variance ratio of the final 250 time steps. In addition, the fitness function used in the genetic algorithm included a term for the stability of the density and mean/variance time series to ensure that the model had reached steady state by the end of the run.

\section{RESULTS}

At the large scale, of the 56 locations sampled, 32 $(\approx 57 \%)$ exhibited signs of $L$. lecanii infection. The number 
of locations in each of the four severity categories were: absent, $24(\approx 43 \%)$; low, $21(\approx 38 \%)$; medium, $3(\approx 5 \%)$; and high, $8(\approx 14 \%)$. There was no obvious pattern underlying the

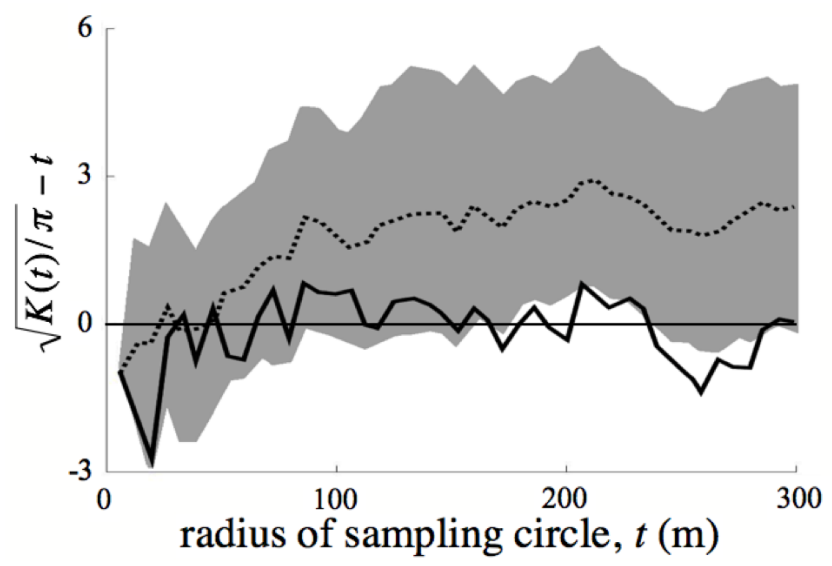

Fig. (1). Graph of transformed Ripley's K versus radius of sampling circle. The dashed line is the average value for 1000 random, simulated fungal distributions. The shaded area delineates $95 \%$ confidence intervals. Simulated distributions were created by randomly allocating the observed instances of fungal presence among the sample points, thereby accounting for the underlying spatial distribution of the sample locations. The solid line is the transformed Ripley's K for the field data.

spatial distribution of the fungus at the scale of the 45 ha plot. According to the Ripley's K analysis, below a sampling circle radius of $\approx 160 \mathrm{~m}$ the distribution of the fungus does not differ significantly from the random expectation (given the underlying distribution of sample points); at some spatial scales above a radius of $\approx 160 \mathrm{~m}$, the distribution is significantly more uniform than random, but at other scales it does not differ significantly from the random expectation (Fig. 1).

At the meso scale, site A has been monitored for the past 4 years, so the sequence of occupation of individual shade trees by $A$. instabilis is known precisely, as shown by the arrows in Fig. (2). The distribution of both scale insects and the white halo fungus disease is also shown in Fig. (2). From previous sampling we know that the distribution of scale insects as a function of distance to the central tree (one of the two occupied four years ago) is decreasing (Fig. 2A). Except for a very large concentration of scale insects within about 5 meters from the shade tree containing $A$. instabilis, the density of scales declines rapidly as the distance from the central tree increases. At a distance of more than 10 meters, the majority of coffee bushes have only a few scale insects, with an occasional tree containing a larger cluster, always tended by a different ant species, although never at the level reached under the protection of $A$. instabilis (Fig. 2). It is worth noting that, although we did not explicitly search for L. lecanii four years ago, it is unlikely that it occurred very commonly since our field notes would have reflected its presence (indeed, it is most likely that L. lecanii was not present at all at this site four years ago).
SITE A

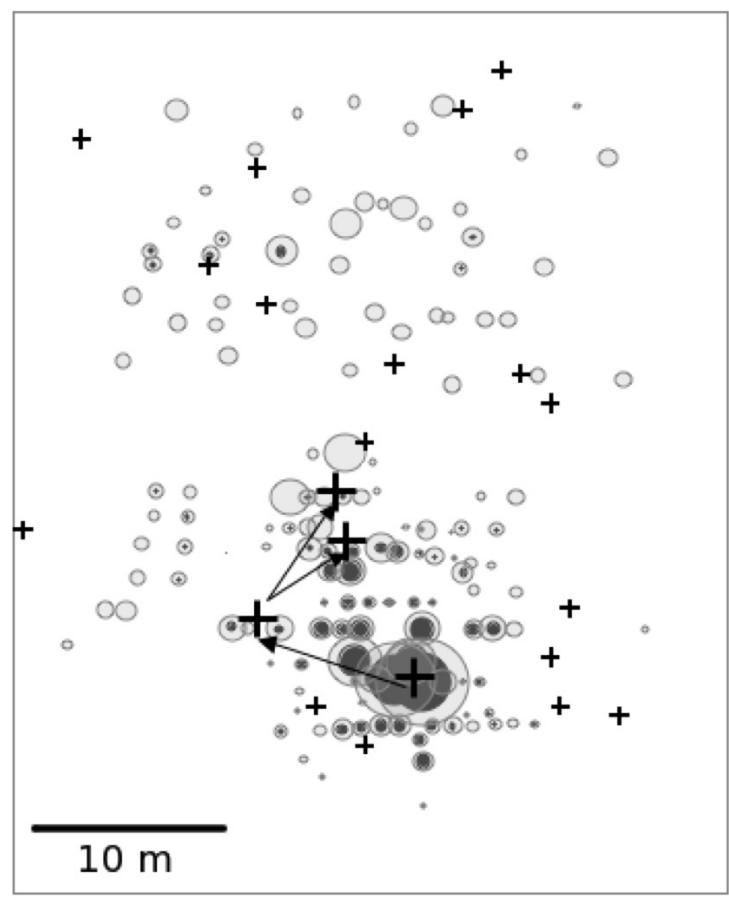

SITE B

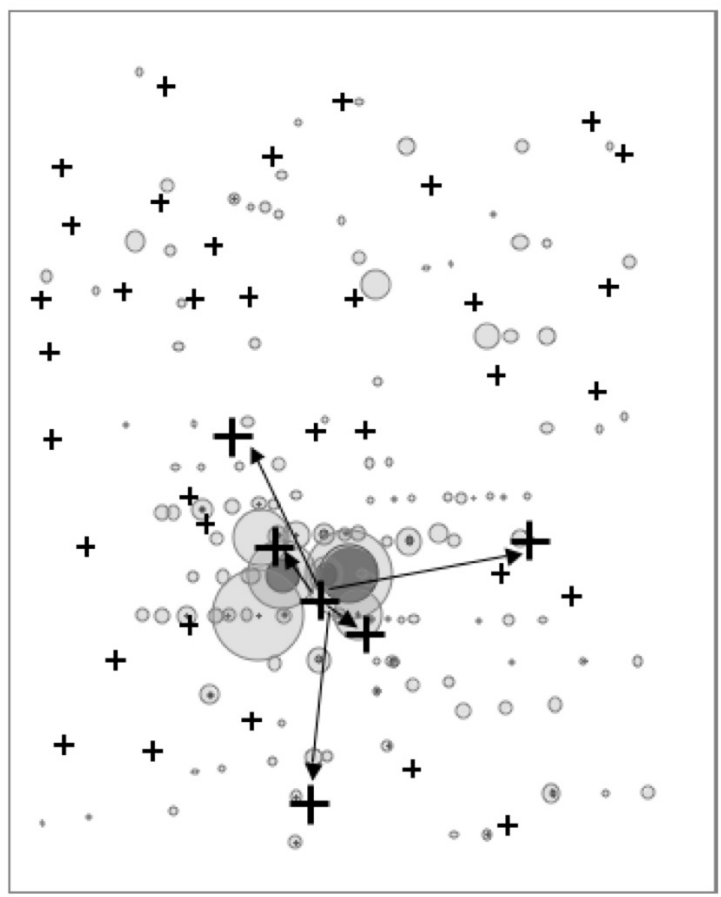

Fig. (2). Representation of two intensively sampled sites in the study area (final sample in June/July, 2008). Site A was occupied by $A$. instabilis at least since 2004, while site B was newly occupied sometime within the past three years. The size of the slightly shaded bubbles is proportional to the number of scale insects per branch of a coffee bush located at that particular coordinate. The size of the darkly shaded bubbles is proportional to the intensity of fungal disease (caused by Lecanicillium lecanii) on that bush. Large crosses indicate positions of shade trees occupied by $A$. instabilis and small crosses indicate positions of unoccupied (and presumably occupiable) shade trees in the system. Arrows indicate presumed direction of spread of the ant colony from historical records. Plots are both 40 X 50 meters. 

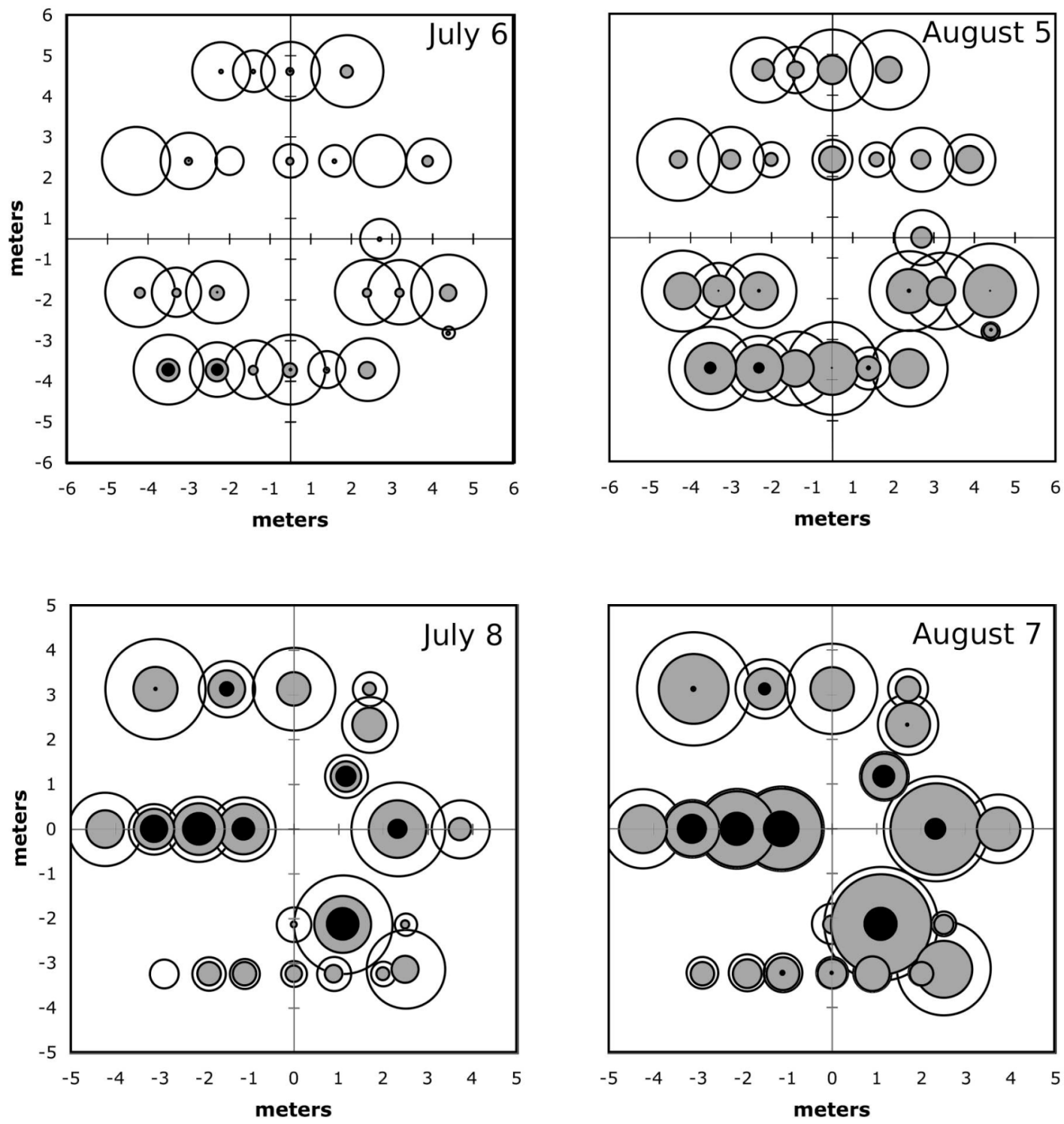

Fig. (3). Scales and fungus in coffee bushes surrounding two shade trees. Shade trees are located at $(0,0)$. The sizes of the white, gray, and black circles are proportional to the number of: total branches, branches with uninfected scale populations, and branches with infected scale populations, respectively. (a) shade tree 1, July 6 and August 5, 2006 (b) shade tree 2, July 8 and August 7, 2006

Site B was sampled in the summer of 2008 , but from previous surveys we know that the entire area surrounding where the six ant-occupied trees are currently located was free of $A$. instabilis colonies until recently (between one and three years prior to the summer of 2008). That is, this particular cluster of ant nests is young, having been established subsequent to 2005 . The population densities of C. viridis are slightly lower than in site $\mathrm{A}$, and the distribution of the white halo fungus disease is more restricted (Fig. 2B), both patterns of which can be explained by the young age of this cluster of ant nests. It is obvious from the field observations that three of the six occupied shade trees are not at all associated with large densities of the scale insects (Fig. 2B), suggesting that they were more recently occupied than the three shade trees around which the high densities of scale insects occur.
At the level of individual shade trees, the initial and final distributions of scales and fungus around the two shade trees are shown in Fig. (3). In the initial survey of the coffee bushes surrounding shade tree \#1 (Fig. 3a), the branches with the largest scale populations were located in two bushes in the lower left quadrant. Some of the scale populations on these bushes were already infected by L. lecanii. By the second census, the number of branches with scale populations in the lower quadrants, i.e., next to the bushes with the largest initial scale populations, had increased substantially, but the fungus was still largely confined to the two original bushes. Between the second and third censuses, scale populations had been established on multiple branches in all of the coffee bushes, but the level of fungus outside of the original two heavily infected bushes remained roughly equal to the initial level ( 6 bushes with 1-2 infected branches in the 

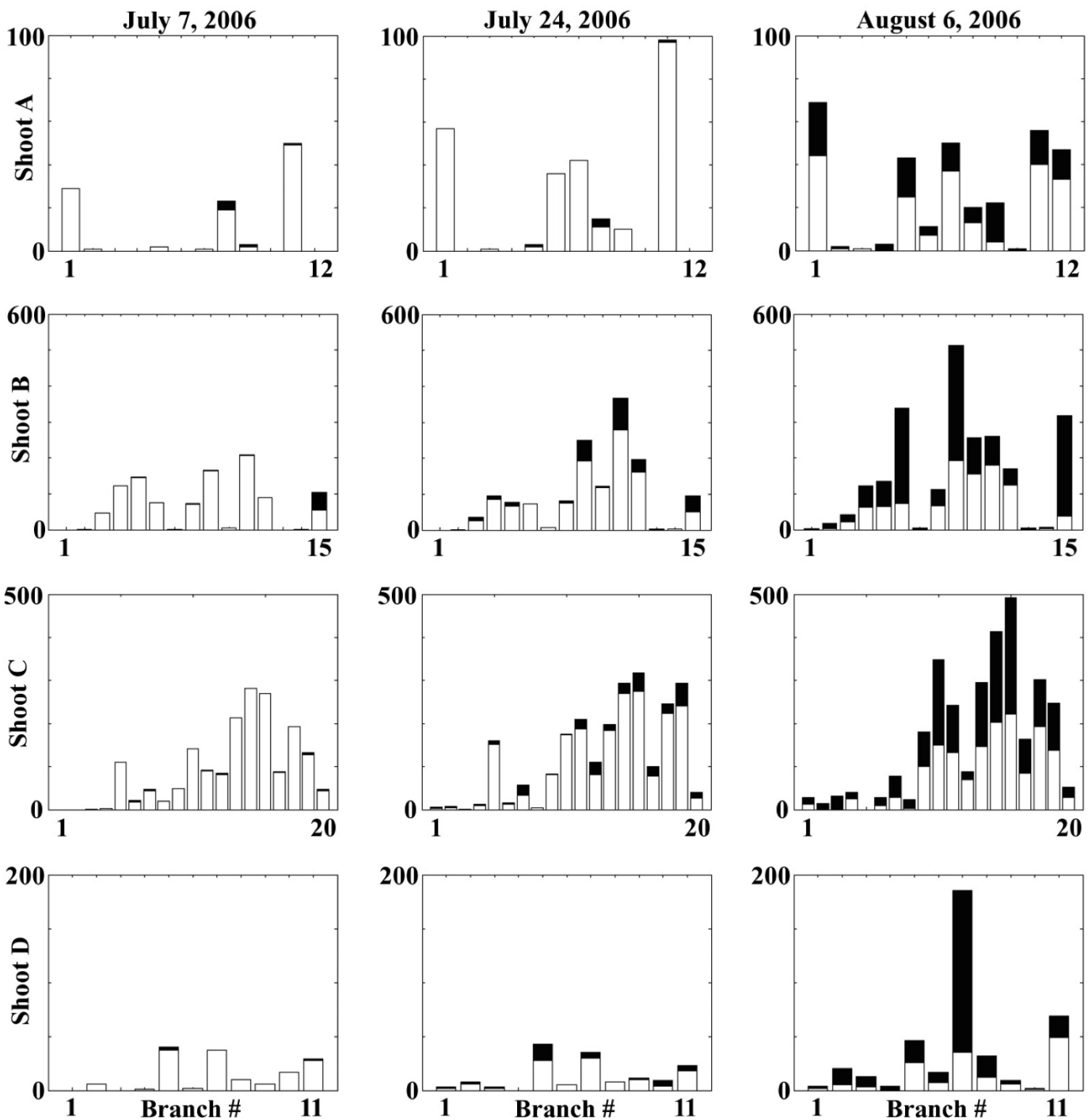

Fig. (4). Number of healthy (white) and infected (black) scales on the branches of 4 shoots on a single coffee bush. Branches with higher numbers are higher on the shoot. Data from three censuses (July 7th, July 24th, and August 6th, 2006) are shown.

initial survey, 7 bushes with 1-4 infected branches in the final survey).

A higher proportion of coffee bushes in the neighborhood of the second shade tree (Fig. 3b) already had established scale populations infected by L. lecanii at the beginning of the census. Throughout the censusing period, there was an increase in the number of branches with scales, but there was not a substantial spread of fungus to previously uninfected coffee bushes; 3 plants that were initially uninfected had 1-2 infected branches by the time of the final survey.

The distribution of healthy and infected scales on each of the four shoots of the coffee bush chosen for the individual coffee plant-level census are shown in Fig. (4). Shoots B and $\mathrm{C}$, which had the largest scale insect populations, reveal pronounced humped distributions of the scales across the branches. Moving from the low branches (small branch numbers) to the high branches (large branch numbers) on the shoots, the size of the scale insect populations generally increased until the top few branches, which generally had much smaller populations per branch due to the relatively small physical size of these younger leaves. Incidence was relatively low in the initial census, with the majority of branches showing little or no evidence of infection. By the second census, L. lecanii infection was more prevalent, but the majority of the scales on all of the branches were still healthy. Between the second and third censuses, there was a general increase in the size of the scale populations and infection by L. lecanii spread to all of the branches, with the populations on many of the branches experiencing $50 \%$ or greater mortality due to L. lecanii.

Using the ant/fungus epizoology CA model, we find it is possible to generate qualitatively and quantitatively similar ant nest spatial distributions using a range of values for $v$ and $t_{l}$. As for parameter estimation using the genetic algorithm, the highest fitness parameter values were confined to a narrow band of $v$ and $t_{l}$ values (Fig. 5), with parameter values away from this region unable to generate the target spatial pattern regardless of the value of $a$. In Fig. (6) we show a representative snapshot of the results of the model with parameters $v=0.35, t_{l}=0.63$, and $a=0.007$. As can be clearly seen, the qualitative nature of the nest clustering reported in Vandermeer et al. (2008) can be reproduced with 


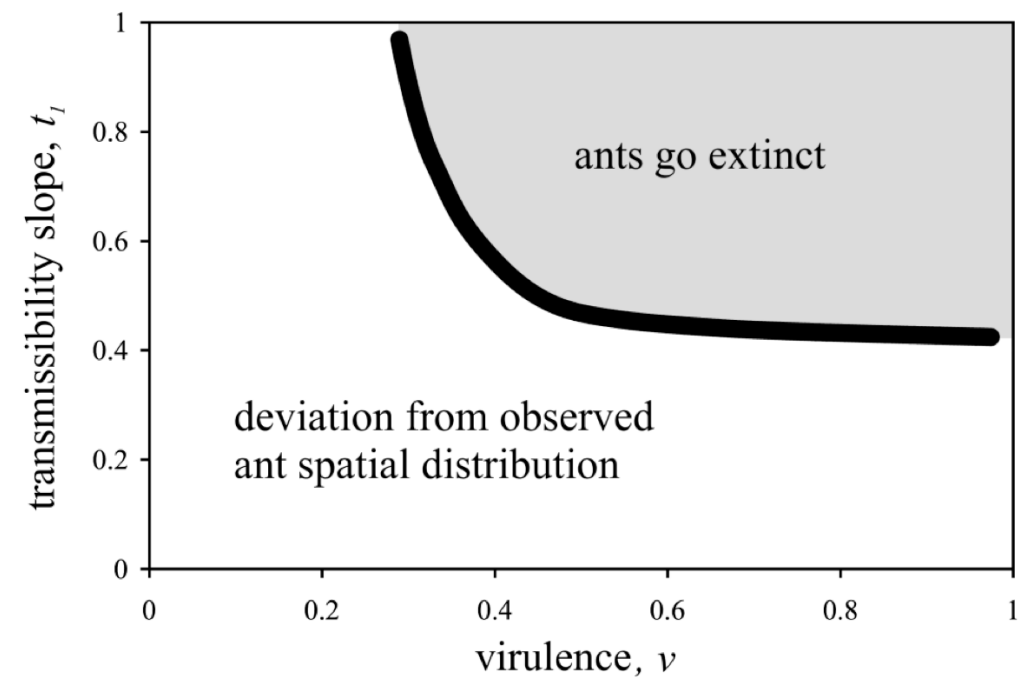

Fig. (5). The black line represents the high-fitness region in $v, t_{l}$ parameter space in which it is possible to generate spatial patterns of ant nests that are qualitatively and quantitatively similar to the pattern observed in the field. Away from this region, it is not possible to generate the observed spatial distribution for $t_{0}=0$ and $a<0.01$; in the gray shaded region, the ants go extinct for most values of $a$.

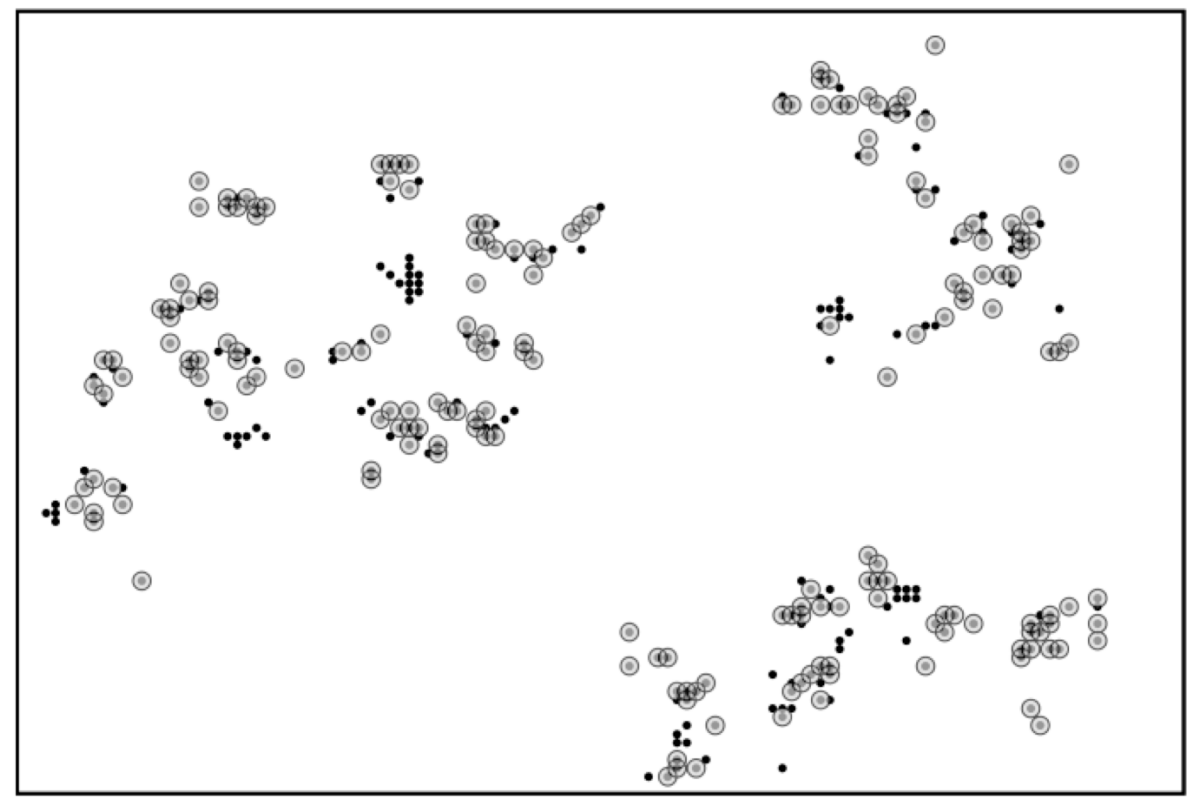

Fig. (6). Example snapshot of the ant and fungus CA model for $v=0.35, t_{0}=0, t_{1}=0.63$, and $a=0.007$. The black dots indicate the locations of ants nests. The shaded circles indicate nest sites infected by L. lecanii. Note that the model only considers the presence of the fungus and not its intensity.

this model. The ranges of densities and mean/variance ratios generated by this model (Fig. 7) also encompass the values for the field samples reported in Vandermeer et al. (2008).

\section{DISCUSSION}

Although the fungus is relatively common in the coffee bushes surrounding ant nests in the 45 ha plot $(\approx 57 \%$ of shade tree neighborhoods sampled showed some signs of $L$. lecanii infection), it is doubtful that the local intensities most commonly encountered are sufficient for the fungus to significantly influence the spatial distribution of ant nests. Therefore, the frequency of high severity fungal infections, which only occurred in $\approx 14 \%$ of the shade tree neighborhoods sampled, is probably the most appropriate measure to consider when assessing the potential influence of $L$. lecanii on pattern formation of the ant nests. 

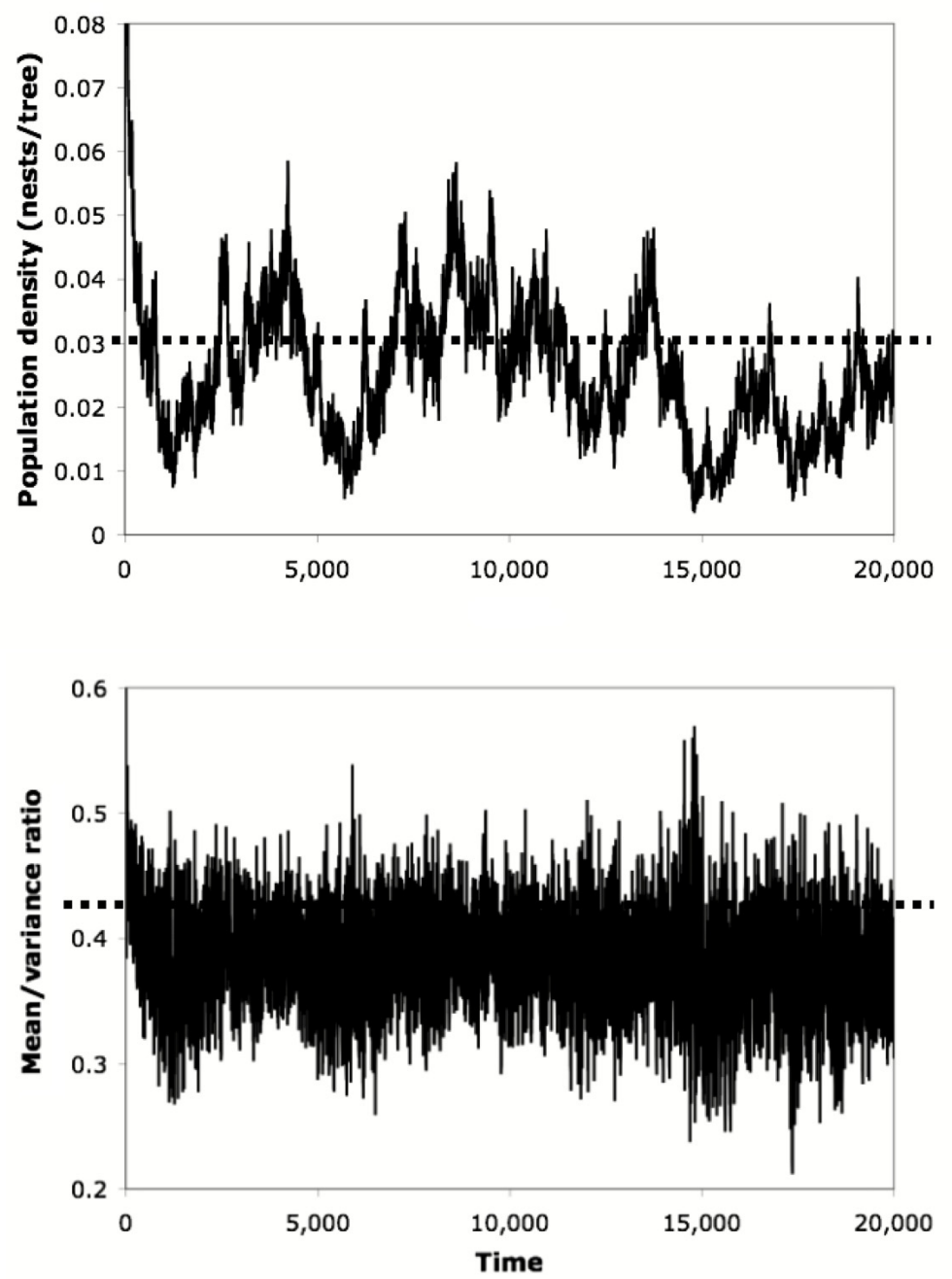

Fig. (7). Time series for a representative run of the ant and fungus CA model for $v=0.35, t_{0}=0, t_{1}=0.63$, and $a=0.007$. Dashed lines indicate the density and mean/variance ratio targets used for the genetic algorithm search. Each model time step corresponds to a six-month interval.

Furthermore, at this large scale, no clear pattern of fungal distribution could be seen, although its presence is widespread. Casual observations prior to the formal survey led us to believe that the fungus was absent in the majority of the area and much more prevalent in one particular half of the plot. However, it was clear from our survey that it is difficult to determine with any certainty whether the fungus is present in a location without examining every single leaf and branch of every coffee bush, as there are many locations where the fungus infects only one or a few scales. Without a thorough search, detecting fungal infections in lightlyinfected locations is unlikely. Therefore, it is perhaps not surprising that a more systematic survey failed to support our preliminary assessment. The fungus was not obviously more prevalent in a particular half of the plot, and the Ripley's K analysis indicates that the distribution of the fungus is not significantly different from random at most spatial scales; if anything, it tends towards a uniform distribution, which is directly opposite of what was suggested by our initial assessment.

Because sporadic infections are common, it is possible that $L$. lecanii is present everywhere in the plot, lying latent in an environmental reservoir. It has been reported that some strains of white halo fungus can persist as saprotrophs in the soil (Eapen et al. 2005, Meyling \& Eilenberg 2006). If the variety in our samples is able to live in the soil, new infections of scale populations in a given location may be more a matter of fungal spores being transmitted from the soil as opposed to the spores being transmitted from active infections on other coffee plants (Jackson, in review). This explanation would be consistent with the wide-ranging, sporadic distribution of the fungus throughout the plot. However, it is important to keep in mind that repeated surveys at a higher spatial resolution might reveal an underlying spatial distribution pattern that was not possible to resolve with the method used in our study.

At the meso scale (Fig. 2) it is possible to deduce the general behavior of the fungal disease if we consider site A four years ago as a base line case (since we did not encounter the fungal disease at that time), site $\mathrm{B}$ in 2008 as an intermediate case and site A in 2008 as a more advanced case. The pattern that exists today, coupled with the pattern of migration of the $A$. instabilis nest, strongly suggests that the ant nest moves partially in response to the fungal 


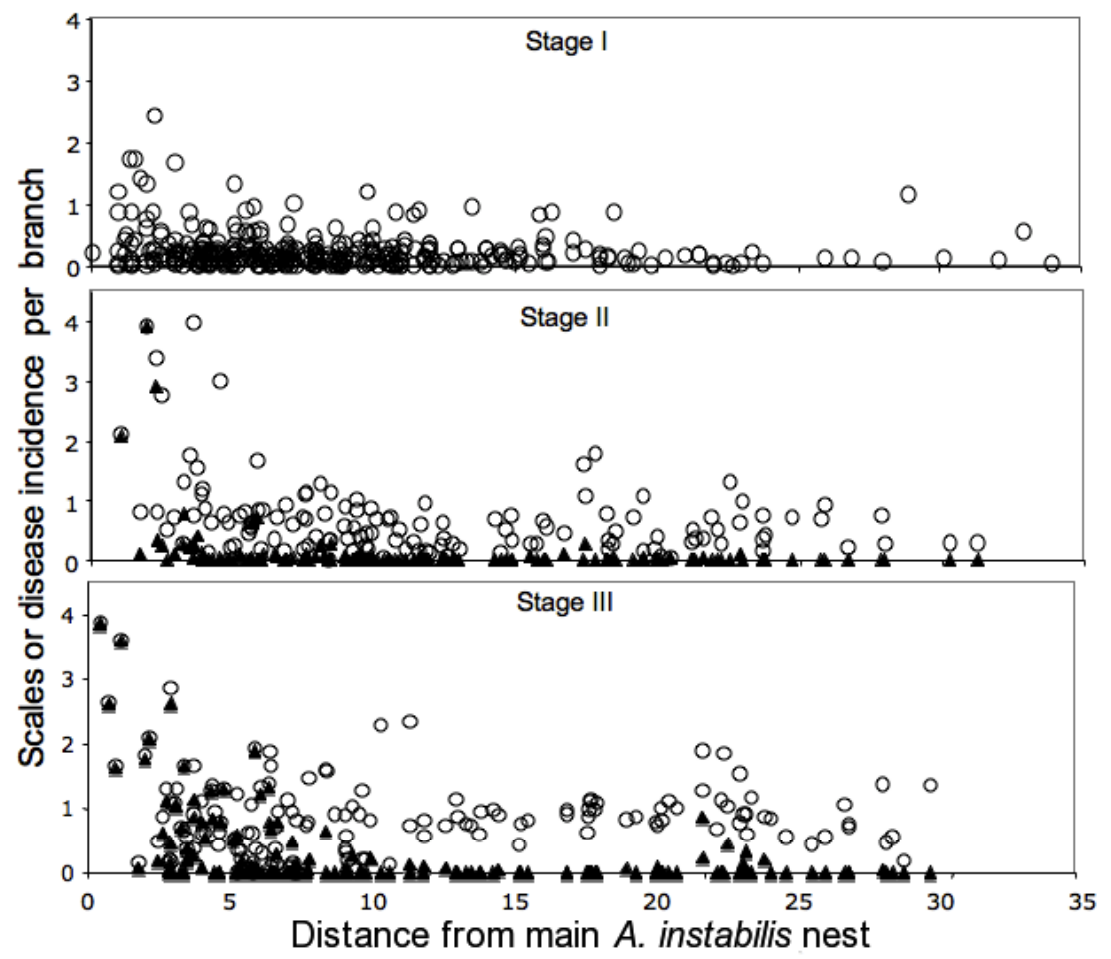

Fig. (8). Data from two sites at two different times, illustrating the stages of development of the fungal pathogen, Lecanicillium lecanii and its host Coccus viridis. Open circles $=C$. viridis (the scale insect), closed triangles $=L$. lecanii (the fungus that causes white halo disease in the scale insect). In all three cases the log of the insect and fungal abundances are plotted as a function of the distance to the main ant nest in the system. In Stage I are the data from site A in 2004, when the fungal disease was absent and the scale populations seemed to be on the increase both locally and in space. In Stage II are the data from site B in 2008, seemingly representing a situation in which the fungal disease has only recently arrived in the area and is beginning its spread throughout the general area, but has not extended much more than five or six meters beyond the initial infective zone. In Stage III are the data from site A again, but from 2008, where we see the major expansion of the fungal disease that seems to be following the expansion of the scale insects in space. Stage IV (not pictured here) is represented in several cases in our plots, in which the entire system, ant-scale-fungus, have locally disappeared entirely.

infection of its main food source, leaving a trace of scale populations devastated by the disease near the locus of the original ant nest site, and scale populations built up but not yet infected nearer to the more recently occupied shade trees. In Fig. (8) we present the log of the intensity of fungal disease along with the log of the scales per branch for those three stages. The progression of both the disease and the scale insects is apparent, the scale insects slowly building up local population densities and dispersing, the fungal disease following in an epizoological fashion.

Part of the dynamics of this system, as is evident from a casual examination of Fig. (2), is the maintenance of $C$. viridis in the absence of the major ant mutualist. That is, once one moves more than approximately 10 meters from the main nest, it is very unlikely that $A$. instabilis will be tending scales. Nevertheless, there are always some bushes to be found with a relatively high concentration of scale insects, although never on the same order of magnitude as when they are with $A$. instabilis. These outliers are always tended by other species of ants (personal observations). Indeed, in a separate study we have encountered almost 80 species of ants that are potential tenders of the scale insects (Philpott et al. 2006). However, none of them has ever been observed as being as effective as A. instabilis, and we have never encountered a coffee bush with more than 250 scale insects that was not under the protection of this primary mutualist. However, those other ants are critical to the system in that they maintain the scales over a large region, albeit at a relatively low density.

Also part of the dynamics is the evident fact that the scales are always present at very low numbers, even in the complete absence of tending ants. While it always appears to field workers that there are zero scales in the absence of one of their ant mutualists, careful searching invariably reveals one or two scales on almost every coffee bush in the plantation. It is most likely that this low but consistent population density is maintained by a continual rain of crawlers blowing around the farm, emanating mainly from the centers established by $A$. instabilis.

Moving to a lower spatial scale, the maps of the fungus in the coffee bushes neighboring a single shade tree suggest that scale populations primarily spread locally from bush to bush, since the bushes with high numbers of branches containing scales tend to be close to one another; this would be consistent with a propagation of scales from one or a few initial populations in a neighborhood of coffee bushes. The censuses performed at the shade tree-neighborhood level indicate that it would be necessary to initiate censuses earlier in the wet season in order to capture the spatial and temporal dynamics of the fungus spread at this spatial scale (Fig. 3). 
It is important to note that $A$. instabilis very probably plays a central role in the dynamics of $L$. lecanii infection of $C$. viridis. Field observations suggest that there is a minimum abundance and density of $C$. viridis that are necessary for an outbreak of L. lecanii to occur. When such an outbreak occurs, the fungus becomes locally epizootic, killing the vast majority of scales on entire coffee bushes. Without A. instabilis tending the scales and therefore providing protection from predators and parasitoids, the scale population is unlikely to reach a sufficient size for a fungal outbreak to occur (Uno 2007).

Considering the results as a whole, a general picture of the overall spatial dynamics emerges. Scale insects initially arrive at coffee plants more-or-less as propagule rain, being carried by the wind. While local increase in scale abundance is clearly from local reproduction, there is also undoubtedly a general dispersion since almost every coffee plant in the entire coffee farm has one or two scale insects on it. The second stage in the overall dynamics depends on ants other than A. instabilis, generally. Acquiring the protection of one of these other ants allows the scale insects to build up a local population density above the normal background density, such that if $A$. instabilis did not exist in the system at all, the local build up of intermediate densities of scales would probably not change, but the size of propagule rain would, since the majority of propagules probably comes from the clusters of $A$. instabilis nests, as reflected in the distribution of scales as a function of distance from ant nests (Figs. 2 and 8). The consequence of these fundamental scale insect spatial dynamics is an approximate general power function distribution of scale insects (Vandermeer \& Perfecto 2006; but see also Alonso \& Pascual 2006, Pueyo \& Jovani 2006, Vandermeer \& Perfecto 2006a), with a very few large clusters of individuals on a coffee bush (never as large as they get under protection of $A$. instabilis), but a huge number of coffee bushes with just a few individuals.

The dynamics of $A$. instabilis thus confronts the prospect of encountering these clusters of scale insects as it searches for additional nesting sites. When an A. instabilis nest seeks to expand its colony, it establishes a satellite colony in a nearby shade tree (occasionally a coffee bush) and begins the search for scale insects and other sources of carbohydrates. Other species of honeydew-producing insects are also sources (Livingston et al. 2008), but the major source is $C$. viridis. Since it is not the case that all individual shade trees harboring an A. instabilis nest are surrounded by coffee bushes with large concentrations of scale insects, it must be the case that occupation of a shade tree is not conditioned by the presence of this mutualist, but rather that the mutualism develops later, probably mainly from the initial clusters of scale insects produced by mutualism with other ants. It remains to be seen exactly what the survival probability of a nest in an individual tree is either with the development of a large $C$. viridis population or not, but it seems a reasonable speculation that a "trial" A. instabilis nest in a new tree may be abandoned if no $C$. viridis population can be cultivated soon. On the other hand, other honeydew-producing insects in the shade trees, as well as extrafloral nectaries in those shade trees may serve this purpose also.

A successful new A. instabilis nest seems to almost always result, eventually, in very large clusters of $C$. viridis within about 5 meters of the nest tree, resulting in a key deviation from the underlying statistical distribution of the scale insects themselves (Alonso \& Pascual 2006; Pueyo \& Jovani 2006; Vandermeer \& Perfecto 2006; 2006a). However, the very large concentrations of $C$. viridis provide a locus for the epizootic development of $L$. lecanii. The dispersal dynamics of the latter are not completely understood, but it is clear that at least three dispersal phenomena are involved: 1) individual scales become infected seemingly at random and not necessarily associated with the local population density of scale insects, 2) epizootic spread of the disease within a high-density population of the scale on an individual branch of a coffee bush occurs predictably, partially as a result of ant foraging (Jackson, in review), 3) local spread from a coffee bush to neighboring coffee bushes also occurs, but in an unpredictable and relatively slow fashion. It is this third mode of dispersal that may have the most important consequences as far as the $A$. instabilis is concerned, for it seems that a local epizootic of white halo fungus spreading locally from bush to bush is one of the causes of the ant nest searching out new shade trees for establishment of satellite nests.

So the general picture emerges of the A. instabilis nest establishing in a new shade tree and searching out local coffee bushes for local concentrations of $C$. viridis. Having encountered local concentrations, the mutualistic effect of the ant permits the scales to build up to extremely high population densities in bushes near to the shade tree containing the new nest. However these extremely large populations of scale insects become targets for the epizootic development of the white halo fungus which, once established in an area, appears to become endemic, following the ant colony around as new shade trees are occupied, eventually, perhaps, resulting in the death of an entire cluster of ant nests (or a large-scale abandonment of the area and migration to some more distant site). This basic natural history generates the rationale for the double CA model, as described in the methods section. The fundamental question to be answered is whether this natural history (as represented qualitatively in the CA model) is capable of producing the self-organized clustering pattern of ant nests that we see in the field; as shown in Fig. (6), the answer is affirmative.

The significance of this mechanism of self-organized spatial pattern is dual. First, it is arguable that the dynamics and propagation of $L$. lecanii creates the conditions for its own survival. Since epizootics only occur when the scale insect population reaches a critical size, and since that critical size only occurs when ants are tending the scales, it is clear that ants are necessary for the production of the epizootics. If the fungal pathogen drives the shifting pattern of the ant/scale mutualism, it could be said that the fungus creates the background conditions that are necessary for its survival because of its potential to influence the spatial distribution of A. instabilis nests. Second, expanding our knowledge of the spatial ecology of this fungal pathogen is important because of the role L. lecanii may play in the biological control of important coffee pests. In addition to attacking $C$. viridis, which has the potential to reach pest status if not under some natural control, $L$. lecanii has also been shown to be a hyperparasite of the coffee rust, Hemileia vastatrix (Shaw 1988, Eskes 1989, Gonzalez et al. 1995). The magnitude and spatial extent of the control of $H$. 
vastatrix by $L$. lecanii clearly depend on the spatial distribution of $L$. lecanii (Vandermeer et al. in press), so obtaining a better understanding of the spatial and temporal characteristics and propagation of L. lecanii is an important component of understanding and improving the biocontrol potential of $L$. lecanii, certainly in the case of the green coffee scale and possibly in the case of the coffee rust.

\section{ACKNOWLEDGEMENTS}

We thank the Peters family for permission to work on their farm. This work was supported by NSF Grant DEB0349388 to J.V. and I.P. and by an International Institute (University of Michigan) Individual Fellowship to D.J. Computational resources were supplied by the Center for the Study of Complex Systems, University of Michigan.

\section{REFERENCES}

Alonso, D \& Pascual, M (2006) Comment on "A keystone mutualism drives pattern in a power function". Science, 313,1739b.

Bascompte, J \& Solé, RV (1998) Spatiotemporal patterns in nature. Trends in Ecology \& Evolution, 13, 173-174.

Bhaskara Reddy, K \& Krishnamoorthy Bhat, P (1989) Effect of relative humidity and temperature on the biotic agents of green scale Coccus viridis (Green). Journal of Coffee Research, 19(2), 828-87.

Chandler, D, Heale, JB \& Gillespie, AT (1993) Germination of the entomopathogenic fungus Verticillium lecanii on scales of the glasshouse whitefly Trialeurodes vaporariorum. Biocontrol Science and Technology 3, 161-164.

Currie, CR (2001) Prevalence and impact of a virulent parasite on a tripartite mutualism. Oecologia, 128, 99-106.

Currie, CR, Ulrich, GM \& Malloch, D (1999) The agricultural pathology of ant fungus gardens. Proceeding of the National Academy of Sciences, 96, 7998-8002.

Eapen, SJ, Beena, B \& Ramana, KV (2005) Tropical soil microflora of spice-based cropping systems as potential antagonists of root-knot nematodes. Journal of Invertebrate Pathology, 88, 218-225.

Easwaramoorthy, S \& Jayaraj, S (1978) Effectiveness of the white halo fungus, Cephalosporium lecanii, against field populations of coffee green bug, Coccus viridis. Journal of Invertebrate Pathology, 32, 88-96.

D. Eskes, AB (1989) Natural enemies and biological control. In: Kushalappa, AC \& Eskes, AB (Eds), Coffee Rust: Epidemiology, Resistance, and Managemen, Boca Raton, FL, CRC Press, 162168.

Feng, KC, Liu, BL \& Tzeng, YM (2000) Verticillium lecanii spore production in solid-state and liquid-state fermentations. Bioprocess Engineering, 23, 25-29.

Gams, W \& Zare, R (2001) A revision of Verticillium sect. Prostrata. III. Generic classification. Nova Hedwigia, 72, 329-337.

Gindin, G, Barash, I, Raccah, B, Singer, S, Ben-Ze'ev, I \& Klein, M (1996) The potential of some entomopathogenic fungi as biocontrol agents against the onion thrips, Thrips tabaci and the western flower thrips, Frankliniella occidentalis. Folia Entomology Hungary 57, $37-42$.

Gindin, G, Geschtovt, NU, Raccah, B \& Barash, I (2000) Pathogenicity of Verticillium lecanii to different developmental stages of the silverleaf whitefly, Bemisia argentifolii. Phytoparasitica, 28, 229239.

Goldberg, DE (1989) Genetic algorithms in search, optimization, and machine learning. Addison-Wesley, Reading, Mass.

Gonzalez, E, Bravo, N \& Carone, M (1995) Caracterización de Verticillium lecanii (Zimm.) Viegas hiperparasitando Hemileia vastatrix Berk y Br y Coccus viridis Green. Revista de Protección Vegetal, 10, 169171.

Goreaud F \& Pélissier, R (1999) On explicit formulas of edge effect correction for Ripley's K-function. Journal of Vegetation Science, $10,433-438$

Hall, RA (1981) The fungus Verticillium lecanii as a microbial insecticide against aphids and scales. In: Burges, HD (Ed), Microbial Control of Pests and Plant Diseases. New York, NY, Academic Press, 483498.

Helms, KR \& Bradleigh Vinson, S (2008) Plant resources and colony growth in an invasive ant: the importance of honeydew-producing hemiptera in carbohydrate transfer across trophic levels. Environmental Entomology, 37, 487-493.

Helyer, N (1993) Verticillium lecanii for control of aphids and thrips on cucumber. IOBC/WPRS Bull, 16, 63-66.

Hsiao, WF, Bidochka, MJ \& Khachatourians, GG (1992) Effect of temperature and relative humidity on the virulence of the entomopathogenic fungus, Verticillium lecanii, towards the oat-bird berry aphid, Rhopalosiphum padi (Hom., Aphididae). Journal of Applied Entomology, 114, 484-490.

Jackson, D (In review) Ant dispersal of an entomopathogenic fungus in a coffee agroecosystem. Journal of Pest Science.

Khalil, SK, Bartos, J \& Landa, Z (1985) Effectiveness of Verticillium lecanii to reduce populations of aphids under glasshouse and field conditions. Agriculture, Ecosystems and Environment, 12, 151-156.

Khalil, SK, Shah, MA \& Naeem, M (1985) Laboratory studies on the compatibility of the entomopathogenic fungus Verticillium lecanii with certain pesticides. Agriculture, Ecosystems and Environment, 13, 329-334.

Kouvelis, VN, Zare, R, Bridge, PD \& Typas, MA (1999) Differentiation of mitochondrial subgroups in the Verticillium lecanii species complex. Letters in Applied Microbiology, 28, 263-268.

Liere, H \& Perfecto, I (2008) Cheating on a mutualism: indirect benefits of ant attendance to a coccidophagous coccinellid. Environmental Entomology, 37, 143-149.

Livingston, GF, White, AM \& Kratz, C (2008) Indirect interactions between ant-tended hemipterans, a dominant ant Azteca instabilis (Hymenoptera: Formicidae), and shade trees in a tropical agroecosystem. Environmental Entomology, 37, 734-740.

Martinez, E, \& Peters, W (1996) La cafeticultura biológica: la finca Irlanda como estudio de caso de un deseño agricoecológico. In: Arriaga, JT, González, FL, Arózqueta, RC \& Lima, PT (Eds), Ecología aplicada a la agricultura: Temas selectos de México. Unidad Xochimilco, DF, Mexico, Universidad Autonomo Metropolitana, $159-183$.

Meyling, NV \& Eilenberg, J (2006) Occurrence and distribution of soil borne entomopathogenic fungi within a single organic agroecosystem. Agriculture, Ecosystems and Environment, 113, 336-341.

Michaud, JP \& Browning, HW (1999) Seasonal abundance of the brown citrus aphid, Toxoptera citricida, (Homoptera: Aphididae) and its natural enemies in Puerto Rico. Florida Entomologist, 82(3), 424447.

Pascual, M, Roy, M, Guichard, F \& Flierl, G (2002) Cluster size distributions: signatures of self-organization in spatial ecologies. Philosophical Transactions of the Royal Society of London B, 357, 657-666.

Perfecto, I \& Vandermeer, J (2008) Spatial pattern and ecological process in the coffee agroforestry system. Ecology 89, 915-920 (Special Feature).

Philpott, SM, Perfecto, I, \& Vandermeer, J (2006) Effects of management intensity and season on arboreal ant diversity and abundance in coffee agroecosystems. Biodiversity and Conservation, 15, 139155.

Pueyo, S \& Jovani, R (2006) Comment on "A keystone mutualism drives pattern in a power function." Science, $313,1739 \mathrm{c}$

Ravensberg, WJ, Malais, M, \& van der Schaaf, DA (1990) Verticillium lecanii as a microbial insecticide against glasshouse whitefly. Proceedings Brighton Crop Protection Conference Pests and Diseases, 1, 265-268.

Reynolds, HT \& Currie, CR (2004) Pathogenicity of Escovopsis weberi: the parasite of the attine ant-microbe symbiosis directly consumes the ant-cultivated fungus. Mycologia, 96, 955-959.

Rietkerk, M, Boerlijst, MC, van Langevelde, F, HilleRisLambers, R, van de Koppel, J, Kumar, L, Prins, HHT \& de Roos, AM (2002) Selforganization of vegetation in arid ecosystems. The American Naturalist, 160, 524-530.

Rodríguez Dos Santos, A \& del Pozo Núñez, E (2003) Aislamiento de hongos entomopatógenos en Uruguay y su virulencia sobre Trialeurodes vaporariorum West. Agrociencia, 7(2), 71-78.

Rohani, P, Lewis, TJ, Grünbaum, D \& Ruxton GD (1997) Spatial selforganization in ecology: pretty patterns or robust reality? Trends in Ecology \& Evolution, 12, 70-74. 
Scanlon, TM, Caylor, KK, Levin, SA \& Rodriguez-Iturbe, I (2007) Positive feedbacks promote power-law clustering of Kalahari vegetation. Nature, 449, 209-213.

Shaw, DE (1988) Verticillium lecanii a hyperparasite on the coffee rust pathogen in Papua New Guinea. Australasian Plant Pathology, 17, 2-3.

Uno, S (2007) Effects of management intensification on coccids and parasitic hymenopterans in coffee agroecosystems in Mexico. Ph.D. dissertation, University of Michigan, United States - Michigan. Retrieved May 16, 2008, from Dissertations \& Theses (a) CIC Institutions database. (Publication No. AAT 3253423)

Vandermeer, J \& Jackson, D (Under revision) Density dependent expansion and control in space, a general case of Turing-like cluster formation.
Vandermeer, J, Perfecto, I \& Philpott, SM (2008) Clusters of ant colonies and robust criticality in a tropical agroecosystem. Nature, 451, 457459.

Vandermeer, J, Perfecto, I \& Liere, H (In press) Evidence for effective hyperparasitism on the coffee rust, Hemileia vastatrix, by the insect pathogen, Lecanicillium lecanii through a complex ecological web. Journal of Phytopathology.

Vandermeer, J \& Perfecto, I (2006) A keystone mutualism drives pattern in a power function. Science, 311, 1000-1002.

Vandermeer, J \& Perfecto, I (2006a) Response to Comments on "A keystone mutualism drives pattern in a power function." Science, 313, 1739 .

Whitley, D (1994) A genetic algorithm tutorial. Statistics and Computing, 4, 65-85.

(C) Jackson et al.; Licensee Bentham Open.

This is an open access article licensed under the terms of the Creative Commons Attribution Non-Commercial License (http://creativecommons.org/licenses/bync/3.0/), which permits unrestricted, non-commercial use, distribution \& reproduction in any medium, provided the work is properly cited. 